\title{
Comment on Reyes et al.: Myocardial perfusion scintigraphy in Europe 2007: a survey of the European Council of Nuclear Cardiology
}

\author{
Ali Gholamrezanezhad
}

Received: 12 January 2012 / Accepted: 17 January 2012 /Published online: 4 February 2012

(C) Springer-Verlag 2012

\section{Dear Sir,}

I read with great interest the recently published article entitled "Myocardial perfusion scintigraphy in Europe 2007: a survey of the European Council of Nuclear Cardiology" [1]. The article provides highly valuable data for those involved in health policy and also nuclear medicine authorities at large. However, I would like to add the following points:

1. Evaluating utilization of an imaging technique per se can be misleading sometimes. In fact, the utilization of each imaging technique should be assessed in the milieu of other competing imaging modalities [2]. For the case of myocardial perfusion scan, CT angiography and stress echocardiography are the main competing modalities [3]. There are a number of reports that shows utilization of these methods, and especially CT angiography, has increased recently [3]. In fact, it is the preference of the referring physicians to screen their patients pre- or postintervention using $\mathrm{CT}$ angiography, not myocardial perfusion scintigraphy. Taking into consideration the volume of competing studies done each year, the $21 \%$ increase in the utilization of myocardial perfusion scintigraphy between 2005 and 2007 sounds more prominent.

2. Although I agree that service provision is becoming more homogeneous within and between countries, we still have to keep in mind however that financial issues, such as gross domestic product (GDP) of each country, is an important contributing factor. Such a difference between Eastern and Western European countries cannot be overlooked easily. Therefore, comparing the utilization pattern of each country with the corresponding GDP can provide the readers with more detailed information and elucidate the socio-economic determinants of health technology utilization $[4,5]$.

\section{References}

1. Reyes E, Wiener S, Underwood SR, European Council of Nuclear Cardiology. Myocardial perfusion scintigraphy in Europe 2007: a survey of the European Council of Nuclear Cardiology. Eur J Nucl Med Mol Imaging 2012;39(1):160-4. doi:10.1007/s00259-011-1923-9.

2. Kuntz EF. Equipment planning. Competing imaging methods slow down nuclear medicine's growth. Mod Healthc 1983;13 (1): 122 .

3. Gholamrezanezhad A, Shirafkan A, Mirpour S, Rayatnavaz M, Alborzi A, Mogharrabi M, et al. Appropriateness of referrals for single-photon emission computed tomography myocardial perfusion imaging (SPECT-MPI) in a developing community: a comparison between 2005 and 2009 versions of ACCF/ASNC appropriateness criteria. J Nucl Cardiol 2011;18(6):1044-52.

4. Demeter S, Reed M, Lix L, MacWilliam L, Leslie WD. Socioeconomic status and the utilization of diagnostic imaging in an urban setting. CMAJ 2005;173(10):1173-7.

5. Gholamrezanezhad A, Mirpour S, Behbahani AA. Nuclear medicine in developing countries: perspective from Iran. J Nucl Med 2010;51 (5): $14 \mathrm{~N}-22 \mathrm{~N}$.

A. Gholamrezanezhad $(\bowtie)$

Research Institute for Nuclear Medicine,

Tehran University of Medical Sciences,

Tehran, Iran

e-mail: gholamrezanejhad@razi.tums.ac.ir 